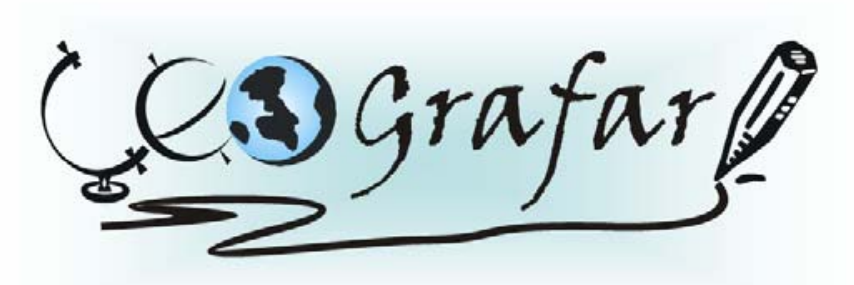

Revista Eletrônica do Programa de Pós-Graduação em Geografla - UFPR

\title{
DINÂMICA DOS VENTOS E TEMPERATURA DO AR EM MARINGÁ, NO VERÃO DE 2004
}

\author{
ANA CLAUDIA CARFAN ${ }^{1}$; JONAS TEIXEIRA NERY ${ }^{2}$; SÔNIA MARIA STIVARI $^{3}$
}

\section{RESUMO}

O presente trabalho tem como objetivo estudar a dinâmica da circulação atmosférica nas primeiras camadas próximas à superfície terrestre, no município de Maringá (PR), região Sul do Brasil. Utilizou-se, o modelo TVM - Topografic Vorticity-Mode e através desse modelo simulou-se a circulação do vento e temperatura do ar, na área de estudo, que corresponde ao Município de Maringá: sua área urbana, rural e seu entorno. Escolheu-se uma situação de verão para este estudo e foram consideradas duas situações de uso de solo a seguir: situação real e atual, considerando o relevo da região e as ações antrópicas; situação atual, com ações antrópicas, mas sem considerar o relevo da região, ou seja, considerando um relevo plano. O modelo Topografic Vorticity-Mode apresentou grande similaridade com a realidade, mostrando as diferenças de temperaturas entre as áreas urbanas e rurais. O modelo simulou razoavelmente a direção e intensidade do vento, demonstrando que a topografia local é mais significativo que o campo térmico gerado pela cidade na determinação dos mesmos. Observou-se ainda a importância da vegetação no declínio da temperatura quando a superfície solo exposto apresentou as temperaturas mais elevadas da área de estudo.

Palavras chaves: temperatura, modelo numérico, clima urbano.

\section{DYNAMICS OF THE WIND AND AIR TEMPERATURE IN MARINGÁ CITY, IN THE SUMMER IN 2004}

\begin{abstract}
The purpose of paper is the study the urban climate and to verify the possible existence of heat island in the Maringá city. In TVM - Topografic Vorticity-Mode model through this model, a simulation of wind circulation and temperatures in that area was performed. The result has showed that not significant temperature trend was observed. TVM - Topografic Vorticity - Mode model presented great similarity with the reality, showing the differences of temperatures between the urban and agricultural areas. The model it presented good results of direction and intensity of the wind, demonstrating that significant the local topography is more important than thermal field generated by the city in the determination of the same ones. Was still observed the importance of the vegetation in the decline of the temperature when the alone surface displayed presented the temperatures highest of the study area.
\end{abstract}

Key words: temperature, numerical model, urban climate.

\footnotetext{
${ }^{1}$ Mestre em geografia, e-mail: acarfan@terra.com.br

${ }^{2}$ Universidade Estadual Paulista UNESP/Ourinhos-SP, e-mail: jonas@ourinhos.unesp.br

${ }^{3}$ Profa. Dr ${ }^{\mathrm{a}}$. do Departamento de Física da Universidade Estadual de Maringá-PR, e-mail: stivari@dfi.uem.br
} 


\section{INTRODUÇÃO}

Com o advento da revolução industrial as cidades passaram a crescer vertiginosamente. Os espaços urbanos foram sendo criados, sem planejamento, para atender a demanda da população que migrava da área rural para as áreas urbanas. As modificações causadas pelo homem na água, no solo e no ar agravaram problemas ambientais e o clima local.

É a partir da Revolução Industrial que os estudos relativos à qualidade de vida urbana têm início, embora seja no século XX, principalmente a partir da Segunda Guerra Mundial, que o desenvolvimento dos mesmos tenha sido mais marcante. Nos últimos trinta anos, aproximadamente, essa temática ganhou relevância na seara de preocupações. Cientistas, políticos, administradores e da sociedade em geral, devido às consideráveis modificações introduzidas pelo processo de urbanização no ambiente precedente e à criação, na maioria das vezes, de condições ambientais prejudiciais à vida, voltaram-se para o estudo do clima urbano, com o objetivo de identificar problemas e buscar soluções.

Quando se constrói espaços urbanos modifica-se o balanço de energia. Uma das principais conseqüências desta alteração é a formação de ilhas de calor que traz grande desconforto, principalmente para as regiões dos trópicos.

Maringá por ser conhecida como uma cidade densamente arborizada e com uma população estimada em 318.952 habitantes (2005), resolveu-se estudar a interferência da urbanização na dinâmica local e as alterações ocorridas na temperatura e na precipitação pluvial ao longo do tempo.

O clima urbano pode ser caracterizado como um sistema de integração entre as características da atmosfera local e as atividades humanas. $\mathrm{O}$ homem, na criação de seu espaço urbano, altera constantemente os diversos parâmetros do clima, tais como, o balanço de energia (SPIRN, 1995).

Os primeiros estudos realizados sobre o clima urbano iniciaram-se em Londres, por Evelyn (1661) e Howard (1833), citados por Lombardo (1985).

OKE (1973) estudou a relação entre o tamanho das cidades norte-americanas e européias, relacionadas ao total de habitantes e a intensidade da ilha de calor e obteve resultados que confirmaram essa relação. Nas áreas tropicais esses estudos são menos numerosos e nas cidades brasileiras é muito recente, datando da década de 1970.

O objetivo deste trabalho foi estudar, através de vento e temperatura, a circulação atmosférica no Município de Maringá e entorno, no verão, bem como analisar o balanço de energia na camada limite dessa região.

\section{Caracterização da área de estudo}

O município de Maringá (Figura 1) situa-se geograficamente no Norte do Paraná, no terceiro Planalto, entre as coordenadas $23^{\circ} 25^{\prime} \mathrm{S}$ e $51^{\circ} 57^{\prime} \mathrm{O}$, sendo cortada ao sul pela linha imaginária do Trópico de Capricórnio, na altura do Cemitério Público. Localizada a 430Km da capital, Curitiba, sua sede urbana possui uma área de $131.224 .500 \mathrm{~m}^{2}$. Possui uma população de 288.653 habitantes, segundo o IBGE (2001) e uma população estimada para 2005 de 318.952 habitantes, www.ibge.gov.br - 03/12/2005.

O clima predominante da região é do tipo subtropical, onde a temperatura média do mês mais frio é inferior a $18^{\circ} \mathrm{C}$ e a temperatura média anual é superior a $20^{\circ} \mathrm{C}$, com verões chuvosos e invernos secos. As massas de ar Equatorial Continental e Equatorial Atlântica, com origem na 
região equatorial, exercem grande influência no clima das regiões sul e sudeste, principalmente na primavera e verão, que, segundo Maack (2002) é subtropical úmido, pertencente ao tipo $C f a$ (clima mesotérmico úmido de verão quente). Deffune (1994), através de uma pesquisa realizada entre 1976 e 1992, afirma que o clima pode ser $C w$ 'h (clima tropical mesotérmico úmido com chuvas de verão e outono). Os dois autores utilizaram à classificação de Köppen (1948).

\section{FIGURA 1 - MAPA DE LOCALIZAÇÃO DA CIDADE DE MARINGÁ NO ESTADO DO PARANÁ.}

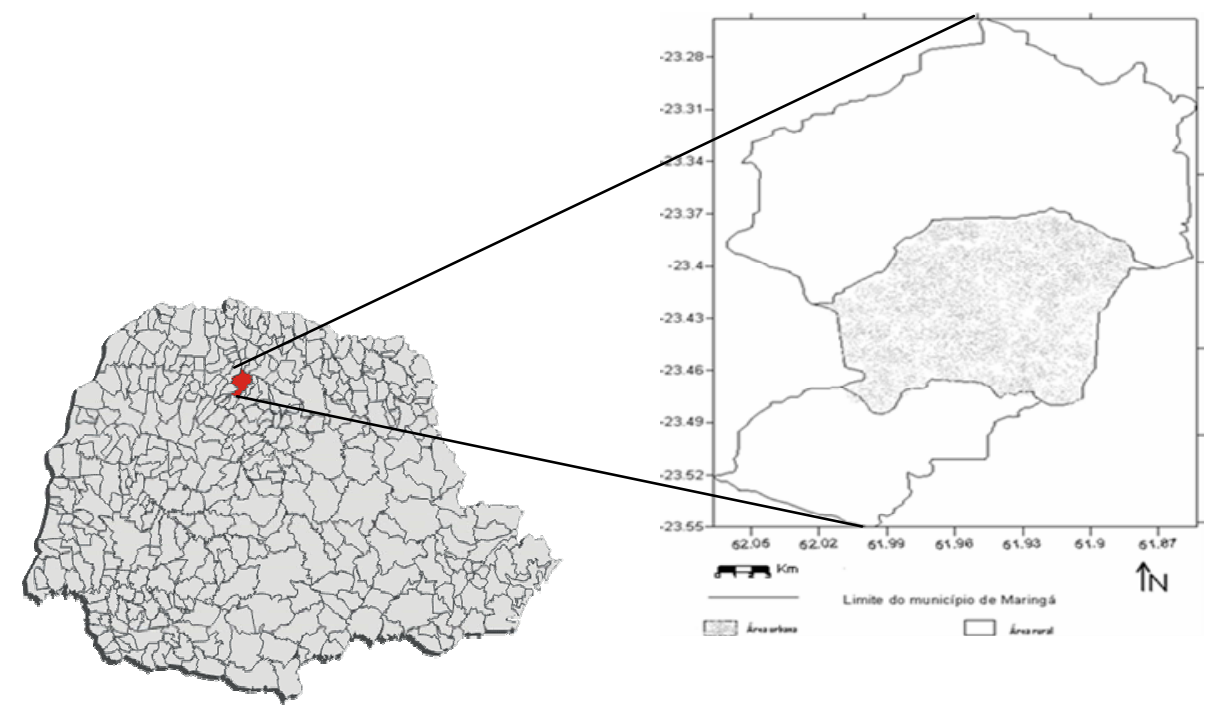

\section{METODOLOGIA E PROCEDIMENTOS}

Foi estudado um dia típico de verão, sendo que a data foi escolhida aleatoriamente, $10 \mathrm{de}$ janeiro de 2005, no Município de Maringá, Noroeste do Paraná. Esta região foi escolhida por apresentar arborização intensa em praticamente toda a área central da cidade. Para esse estudo foi utilizado o modelo Topografic Vorticity-Mode Mesoscale- $\beta$ (TVM-30C).

Foram utilizadas imagens de satélites fornecidas pelo Instituto Nacional de Pesquisas Espaciais (INPE), dos dias 28/03/2004 e 17/01/2004. Essas imagens foram utilizadas para o estudo espacial da área e para inicialização do modelo TVM. O critério de escolha desses dias, para a obtenção das imagens, partiu da base que o modelo TVM requer dias com céu claro, ou seja, sem nuvens. Foram utilizadas as bandas 3, 4 e 5, que possibilitou uma melhor visualização do uso de solo e vegetação. Os horários escolhidos para a análise da evolução da camada limite foram às $15 \mathrm{~h}$ e às $18 \mathrm{~h}$. Às $15 \mathrm{~h}$ tem-se uma maior radiação solar incidente e às $18 \mathrm{~h}$ essa radiação torna-se consideravelmente atenuada, contrastando o balanço energético.

O modelo TVM-30C foi desenvolvido por Bornstein (1975), com nome de URBMET, uma versão hidrostática e bi-dimensional, para estudar a estrutura da camada limite de áreas urbanas em terrenos planos.

Bornstein et al., (1986) expandiram o URBIMET para três dimensões ainda na forma hidrostática e utilizaram o modelo para simular a influência da área urbana sobre as frentes da brisa marítima na cidade de Nova Iorque, Estados Unidos. 
Uma nova versão foi desenvolvida por Schayes e Thunis (1990), denominada TVM e incluindo os efeitos da topografia.

Thunis e Clappier (2000) descreveram as fórmulas e aplicações do modelo não-hidrostático, o TVM e fazem uma comparação com o modelo bi-dimensional.

Karam et al., $(1995,1996)$ utilizou o modelo para simular a circulação induzida termicamente pela topografia na região de Iperó (SP) e para simular a evolução temporal e espacial da Camada Limite Planetária (CLP) na dispersão de $\mathrm{SO}_{2}$ na região de Candiota (RS).

Stivari (1999) fez um estudo da brisa lacustre do lago formado pela hidrelétrica de Itaipú, onde utilizou dados de temperatura, umidade relativa do ar e precipitação pluvial de estações climatológicas, além de um balão de radiossondagem e, através do modelo TVM, estabeleceu o papel dominante da brisa sobre a região.

Na utilização do modelo, para a simulação da circulação do vento e da temperatura no nível do solo e em $15 \mathrm{~m}$, foram utilizadas duas imagens de satélites, Landsat-5/TM, fornecidas pelo Instituto Nacional de Pesquisas Espaciais (INPE), dos dias 28/03/2004 e 17/01/2004. Essas imagens foram utilizadas para o estudo espacial da área e transformadas em grades para serem utilizadas no modelo TVM. O critério de escolha desses dias, para a obtenção das imagens, partiu da base que o modelo TVM requer dias com céu claro, ou seja, sem nuvens. Foram utilizadas as bandas 3,4 e 5, que possibilitou uma melhor visualização do uso de solo e vegetação. Os horários escolhidos para a análise da evolução da camada limite foram às $15 \mathrm{~h}$ e às $18 \mathrm{~h}$. Às $15 \mathrm{~h}$ tem-se uma maior radiação solar incidente e às $18 \mathrm{~h}$ essa radiação torna-se consideravelmente atenuada, contrastando o balanço energético.

\section{RESULTADOS E DISCUSSÃO}

\section{Direção e Intensidade do Vento e da Temperatura}

Para se ter uma visão mais espacial da variabilidade da temperatura do ar e do vento, utilizouse o modelo TVM, com dados de entrada do modelo de acordo com as Tabelas 1 e 2.

Na Figura 2 tem-se o mosaico das imagens de satélite Landsat-5 TM dos dias 17/01/2004 e 28/03/2004, onde se pode ver ao centro a cidade de Maringá (observar os contornos na parte central do mosaico). Foram escolhidas as bandas 3, 4 e 5 por serem as que melhor representam as ocupações de solo a serem estudadas. A resolução utilizada para trabalhar a imagem foi de $1000 \mathrm{~m}$.

TABELA 1 - DADOS DE ENTRADA DO MODELO

\begin{tabular}{lll}
\hline & Inverno & Verão \\
Dia juliano & 191 & 10 \\
Latitude (decimais) centro da grade & -23.41 & -23.41 \\
Longitude (decimais) centro da grade & -51.93 & -51.93 \\
Temperatura média do $1^{\circ}$ nível do modelo & $290.15 \mathrm{~K}$ & $297.95 \mathrm{~K}$ \\
Razão de mistura á superfície & 0.012 & 0.018 \\
Hora local do início da simulação & $6 \mathrm{~h}$ & $6 \mathrm{~h}$ \\
Duração Máxima da simulação & $24 \mathrm{~h}$ & $24 \mathrm{~h}$ \\
\hline
\end{tabular}

FONTE: O AUTOR 
TABELA 2 - PROPRIEDADES TÉRMICAS E RADIOATIVAS DAS SUPERFÍCIES

\begin{tabular}{|c|c|c|c|c|c|c|c|c|c|}
\hline Superfície & Albedo & Emissividade & $\begin{array}{l}\text { Resistência } \\
\text { superficial } \\
\quad(\mathrm{s} / \mathrm{m})\end{array}$ & $\begin{array}{c}\text { Cap. } \\
\text { térmica } \\
\left(\mathrm{Jm}^{-3} \mathrm{~K}^{-1}\right) \\
\left(\mathrm{x} 10^{6}\right)\end{array}$ & $\begin{array}{l}\text { Comprimento } \\
\text { de rugosidade } \\
\text { (m) }\end{array}$ & $\begin{array}{c}\text { Temp. } \\
\text { do } 1^{\circ} \\
\text { nível } \\
(\mathrm{K}) \\
\text { (verão) }\end{array}$ & $\begin{array}{l}\text { Temp. } \\
\text { do } 2^{\circ} \\
\text { nível } \\
\text { (K) } \\
\text { (verão) }\end{array}$ & $\begin{array}{l}\text { Temp. } \\
\text { do } 1^{\circ} \\
\text { nível }(\mathrm{K}) \\
\text { (inverno) }\end{array}$ & $\begin{array}{c}\text { Temp. } \\
\text { do } 2^{\circ} \\
\text { nível }(\mathrm{K}) \\
\text { (inverno) }\end{array}$ \\
\hline $\begin{array}{l}\text { Vegetação } \\
\text { alta }\end{array}$ & 0.09 & 0.95 & 169.2 & $2.70 \mathrm{e}+05$ & 0.507 & 299.0 & 300.0 & 292.3 & 291.8 \\
\hline $\begin{array}{l}\text { Vegetação } \\
\text { baixa } \\
\text { Solo }\end{array}$ & 0.10 & 0.95 & 117.1 & $2.70 \mathrm{e}+05$ & 0.115 & 299.0 & 300.0 & 292.3 & 291.8 \\
\hline exposto & 0.16 & 0.95 & 400.0 & $1.65 \mathrm{e}+05$ & 0.049 & 299.0 & 300.0 & 292.3 & 291.8 \\
\hline Urbana & 0.10 & 0.95 & 300.0 & $1.94 \mathrm{e}+05$ & 0.232 & 299.0 & 300.0 & 292.3 & 291.8 \\
\hline Água & 0.07 & 0.98 & 1.0 & $4.18 \mathrm{e}+05$ & 0.001 & 302.0 & 302.0 & 292.3 & 291.8 \\
\hline
\end{tabular}

FONTE: BANCO MUNDIAL (2004)

FIGURA 2 - MOSAICO DAS IMAGENS DE SATÉLITE. COMPOSIÇÃO REALIZADA COM DUAS IMAGENS, OBTIDAS JUNTO AO INSTITUTO NACIONAL DE PESQUISAS ESPACIAIS (INPE).

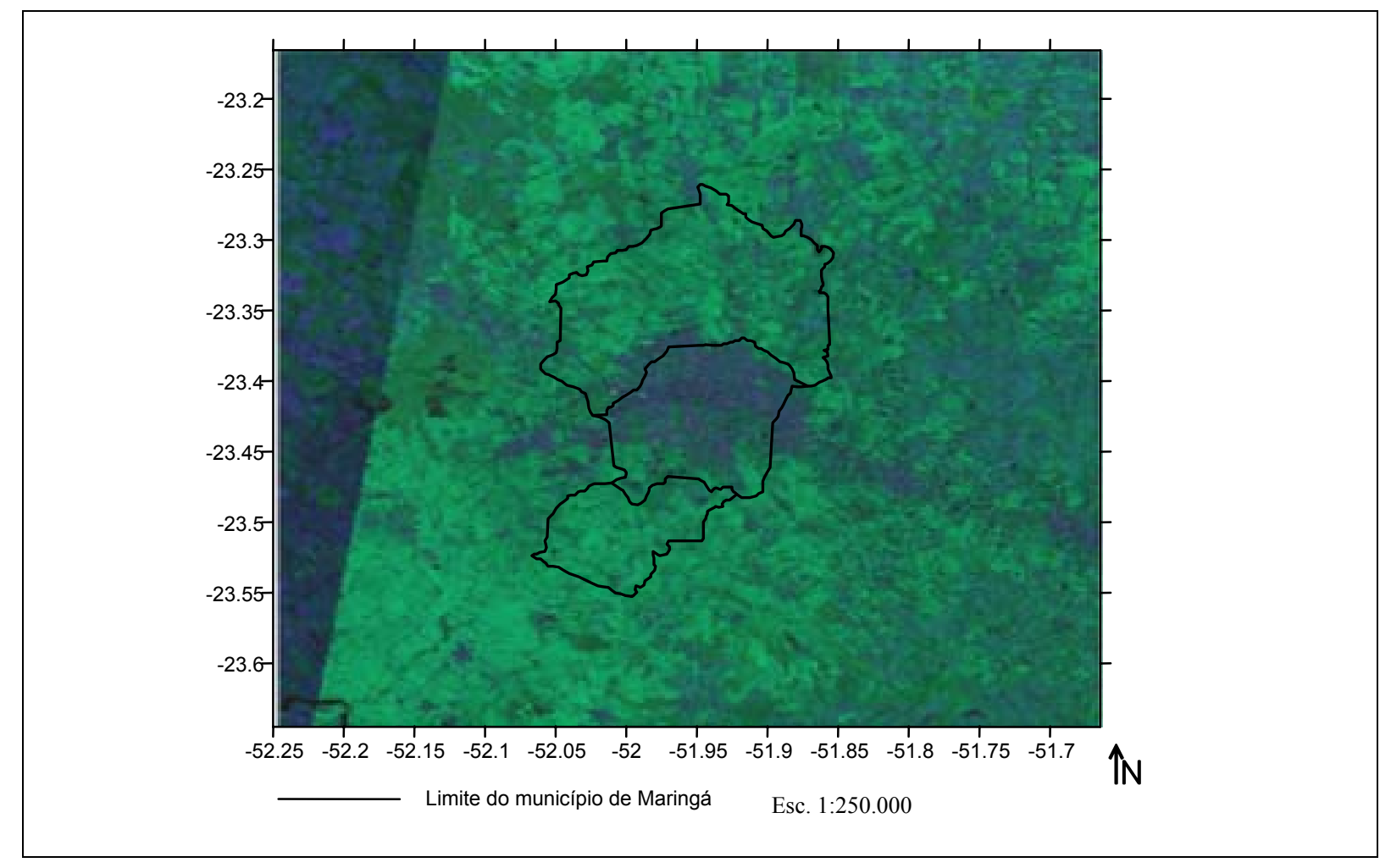

A Figura 3 mostra o mesmo mosaico, mas agora com a imagem classificada, onde se diferenciam cinco tipos de uso de solos classificados. Observou-se a predominância de vegetação baixa que representa áreas agrícolas seguida de vegetação alta, representada por árvores mostrando áreas de preservação e parques dentro da área urbana. Apesar de a área de estudo englobar o rio Pirapó, na resolução trabalhada não foi possível identificá-lo. Pode-se apenas observar a superfície "água" em uma pequena parte mais ao sul pertencente ao rio Ivaí. Na superfície solo exposto, que representa o solo sem vegetação, podendo ser considerado um solo preparado para o plantio, notou-se pequena ocorrência na área urbana. 
FIGURA 3 - IMAGEM CLASSIFICADA SEGUNDO O TIPO DE USO DE SOLO, ATRAVÉS DO SOFTWARE SPRING.

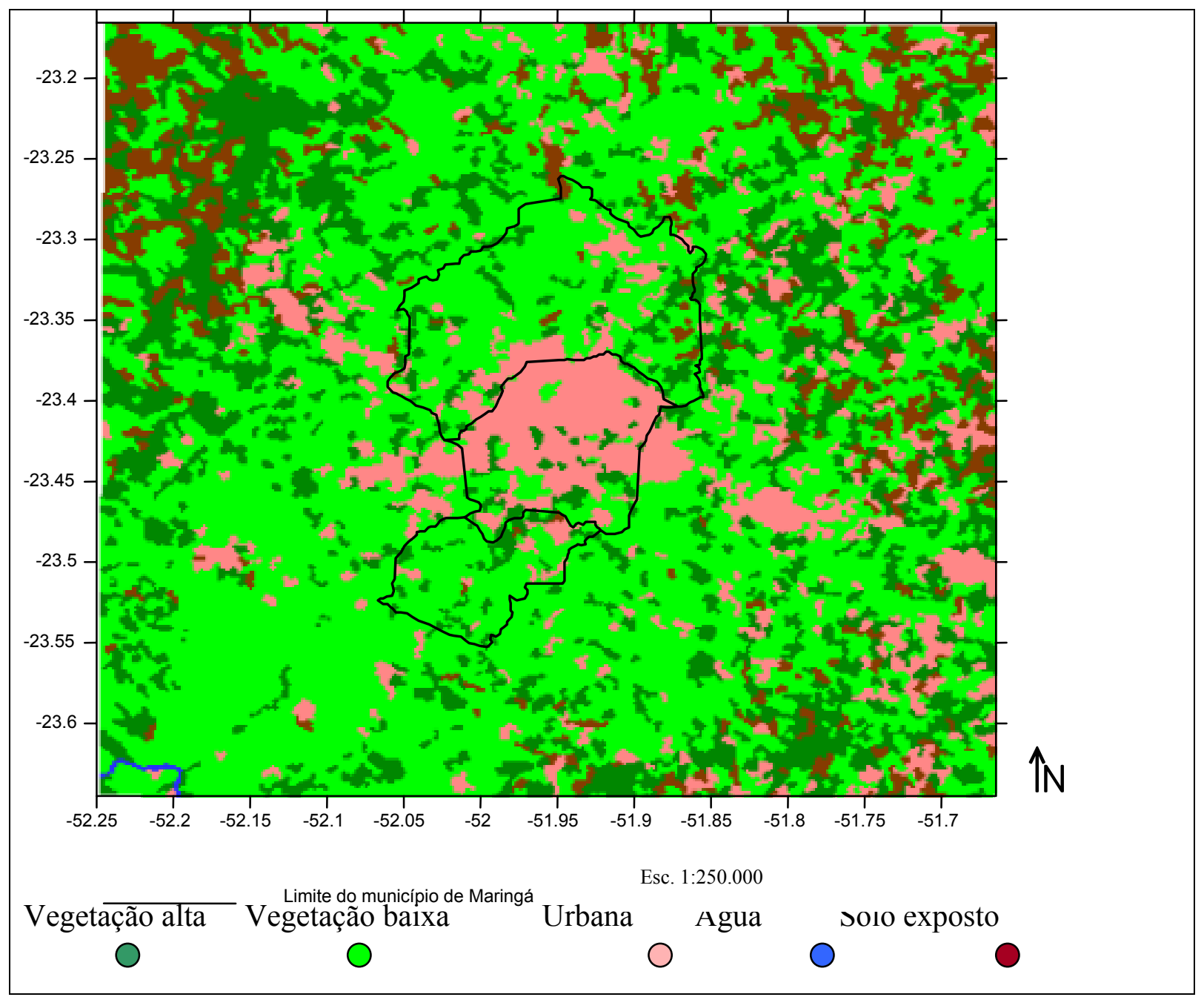

A Figura 4 refere-se ao relevo da região onde se observa que Maringá situa-se entre 500 a $600 \mathrm{~m}$ de altitude.

FIGURA 4 - CONFIGURAÇÃO DO RELEVO DA REGIÃO DE ESTUDO, REALIZADA ATRAVÉS DO SOFTWARE SURFER.

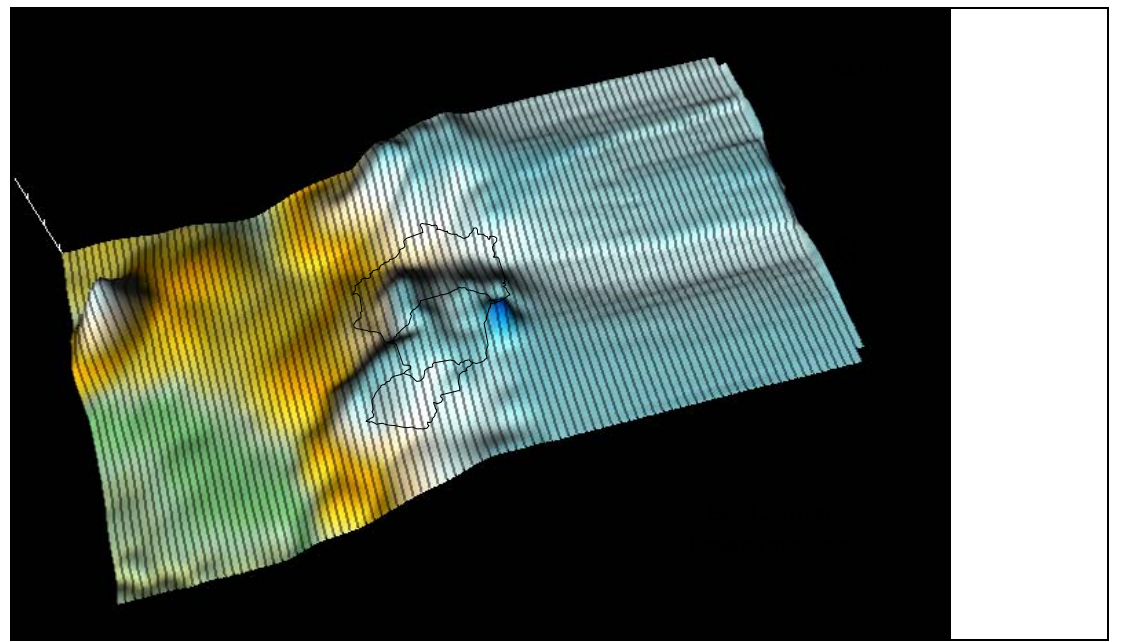


Na Figura 5 tem-se uma imagem de satélite, apresentando intensa nebulosidade sobre o Estado do Paraná e, por conseguinte a cidade de Maringá. Esse padrão de nebulosidade está presente na região Sul e Sudeste, a partir de outubro, estendendose até março do ano seguinte. Deve-se ressaltar que o modelo utilizado não detecta a presença dessas nuvens, sendo um fator limitante para a análise de toda a dinâmica, no estudo do clima urbano da área.

Esta configuração, apresentada na Figura 5, está associada à convecção profunda da Amazônia, com entrada de massa polar, proveniente do extremo sul da América do Sul. A partir de setembro, a radiação solar é mais intensa no Hemisfério Sul, provocando maior liberação do calor latente e sensível sobre a Amazônia, intensificando a massa equatorial continental $(\mathrm{mEc})$, também denominada de Zona de Convergência do Atlântico Sul. Os ventos alísios que sopram de leste para oeste transportam essa umidade na direção do Oceano Pacífico, mas a cordilheira dos Andes barra a penetração dessa massa no oceano, fazendo-a deslocar sobre o continente sul americano, principalmente o Brasil central. Também faz parte desse mecanismo de transporte a célula de Hadley que transporta energia, massa e momentum para as regiões tropicais (NERY, 2002).

Essa dinâmica apresentando muitas nuvens é uma limitação do modelo, que requer dias claros e sem nuvens. Por isso foram escolhidos aleatoriamente dias claros (céu sem nuvens) tanto para o verão quanto para o inverno.

FIGURA 5 - PERÍODO DE MAIOR INTENSIDADE DE CONVECÇÃO SOBRE A REGIÃO NORTE, SUDESTE E SUL DO BRASIL, DEVIDO A PRESENÇA DE UMA ZONA DE CONVERGÊNCIA SOBRE ESSAS REGIÕES.

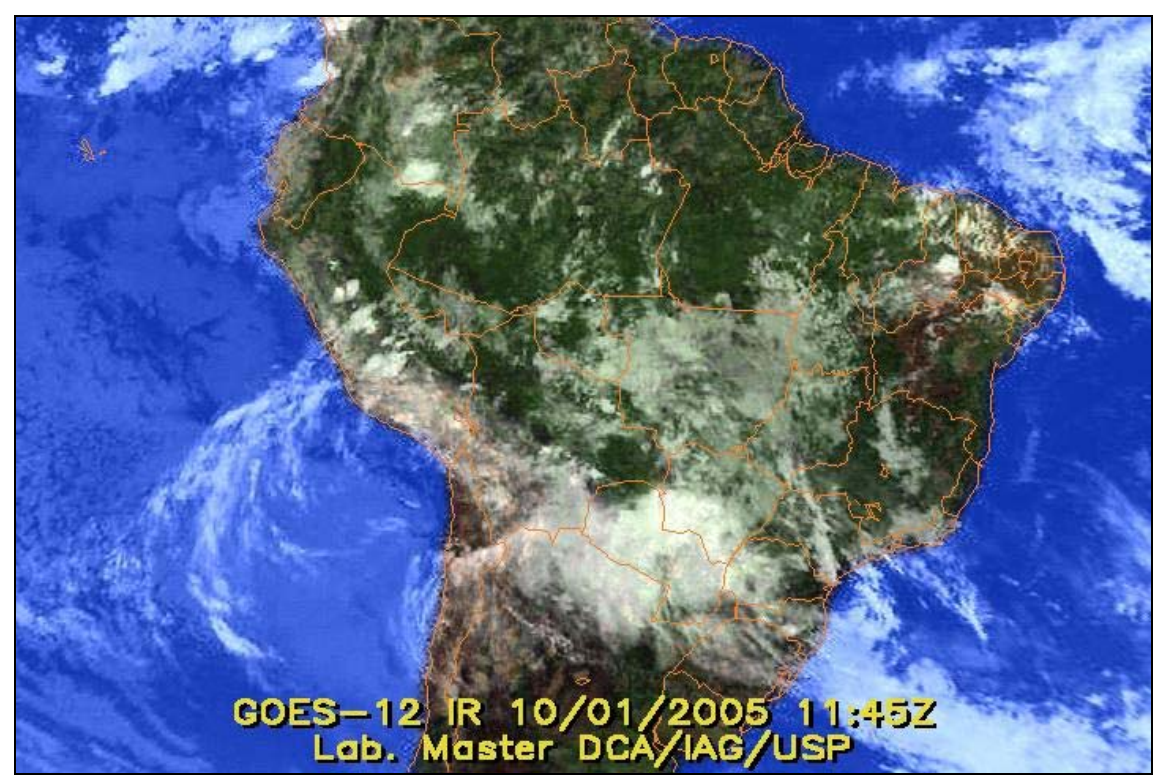

FONTE: IMAGEM DE SATÉLITE - INSTITUTO ASTRONÔMICO E GEOFÍSICO (IAG), USP.

Com base na Figura 6A, pode-se observar isotermas obtidas a partir do modelo. As temperaturas na área analisada variaram entre 33 e $44.5^{\circ} \mathrm{C}$, sendo, portanto, um gradiente térmico significativo de $11^{\circ} \mathrm{C}$, aproximadamente. Isso se deve a presença da área urbana, por um lado, com temperatura de $39.5^{\circ} \mathrm{C}$ e, por outro lado, áreas com solo exposto, cuja temperatura é de, aproximadamente, $44^{\circ} \mathrm{C}$. Na área urbana observaram-se algumas áreas com temperaturas de $38^{\circ} \mathrm{C}$. Pode-se inferir que nessas áreas encontram-se os dois principais 
bosques da cidade. O rio Ivaí, localizado no sudoeste da área de estudo apresentou as menores temperaturas, com valor de $33^{\circ} \mathrm{C}$, aproximadamente.

FIGURA 6A - RESULTADO OBTIDO ATRAVÉS DO MODELO: ANÁLISE DAS ISOTERMAS, NA SUPERFÍCIE, ÀS 15 HORAS.

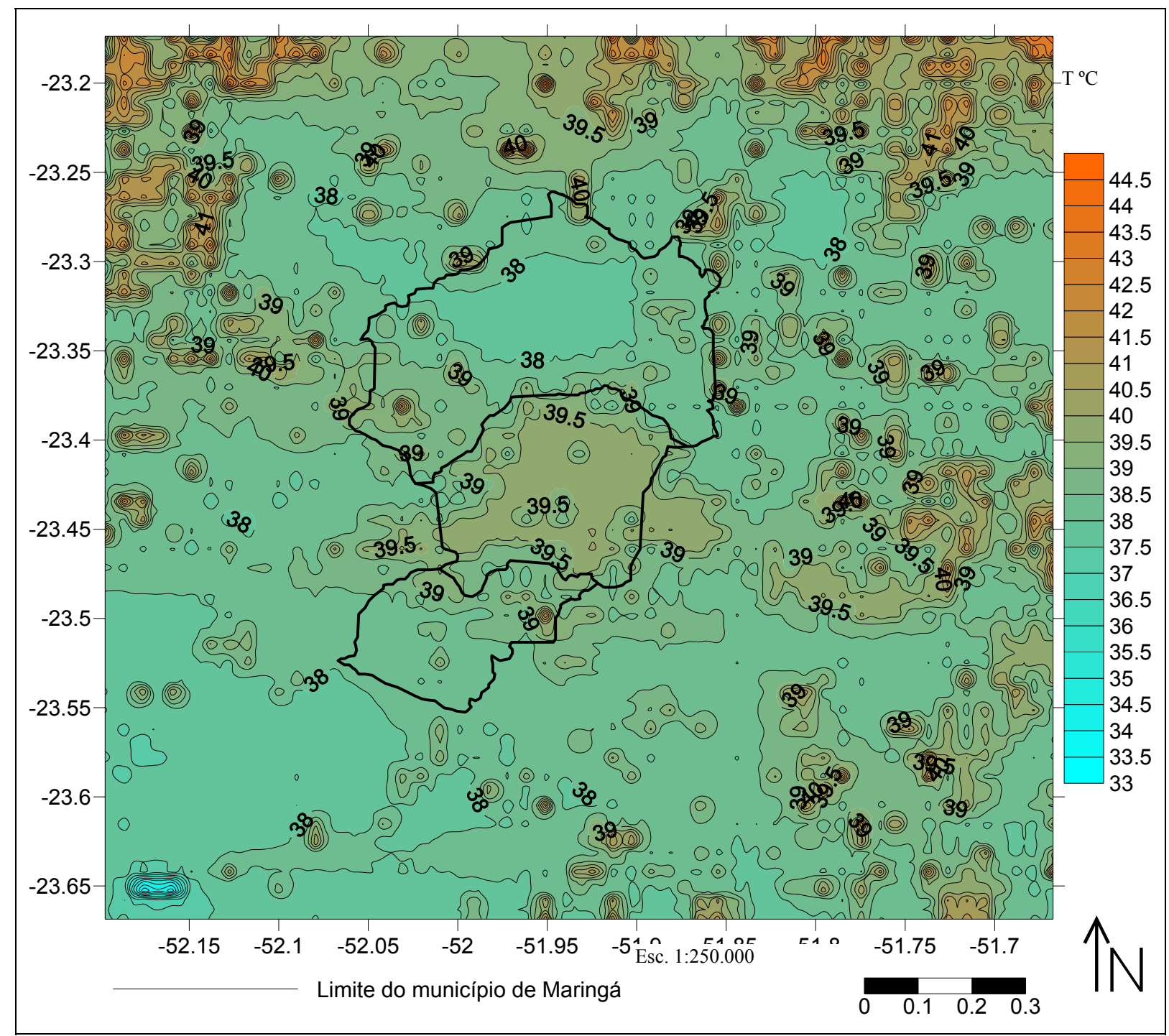

Com relação à Figura 6B, pode-se observar variabilidade tanto na direção quanto na intensidade do vento, em relação à área de estudo e para um dia de verão. Os ventos são intensos no cone urbano do município de Maringá, com velocidade máxima de $6 \mathrm{~m} / \mathrm{s}$ e direção nordeste. Também há predomínio de direção nordeste na zona rural (área superior ao cone urbano), com velocidade máxima de $5 \mathrm{~m} / \mathrm{s}$, assim como na área rural (área inferior do cone urbano), sem vento com direção predominante, ou seja, variabilidade na direção nordeste e sudeste e intensidade de 4 a $5 \mathrm{~m} / \mathrm{s}$. 
FIGURA 6B - RESULTADO OBTIDO ATRAVÉS DO MODELO: ANÁLISE DAS ISOTERMAS, NA SUPERFÍCIE E DIREÇÃO DO VENTO ÀS 15 HORAS.

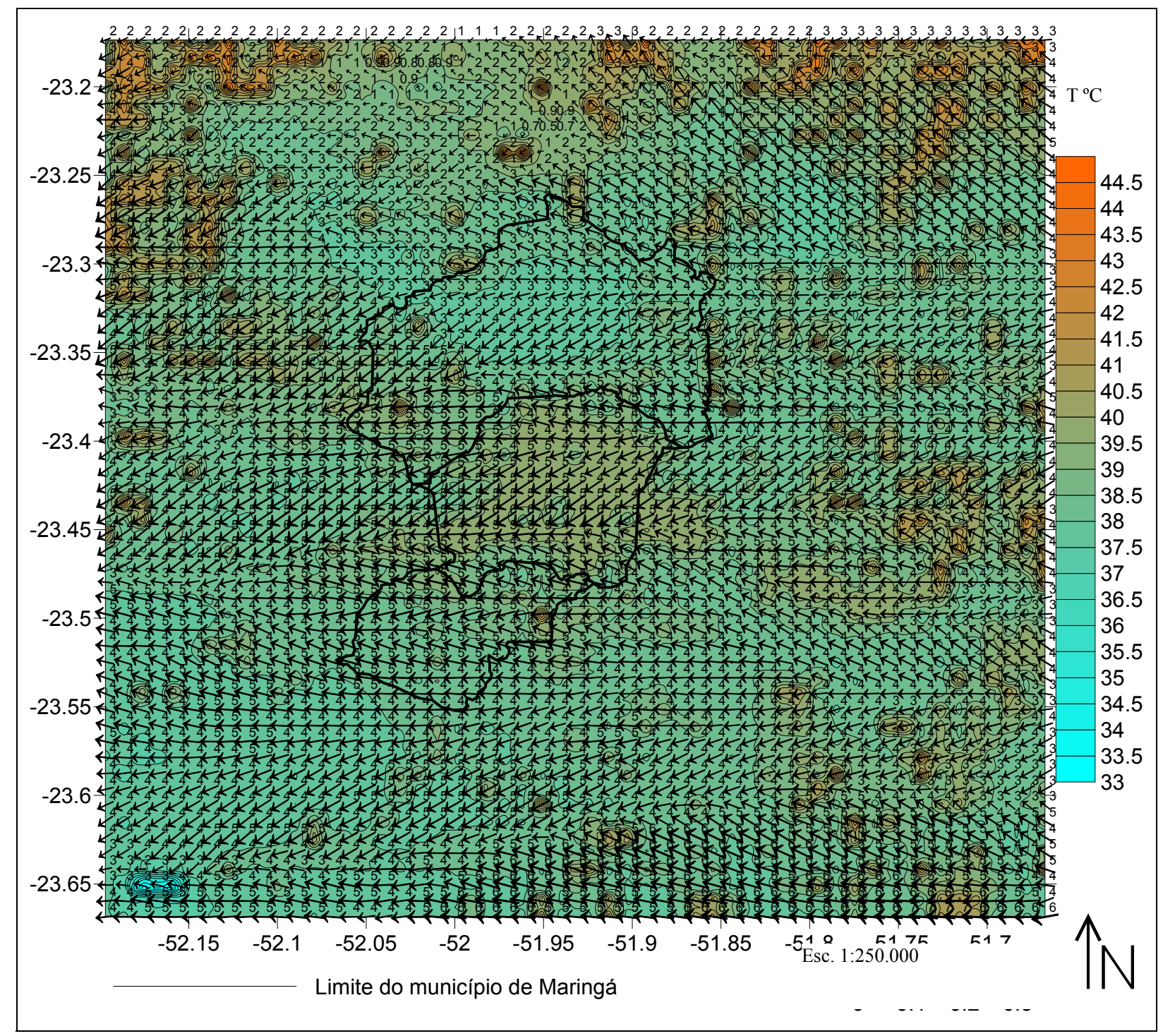

Na Figura 7A, pode-se observar isotermas das 18h, obtidas através do modelo TVM. Estas isotermas apresentaram marcada variabilidade, com valores entre $31^{\circ} \mathrm{C}$ (no rio Ivaí, parte inferior da figura à esquerda) e $36.5^{\circ} \mathrm{C}$ (área de solo exposto, mais concentrada na parte superior da figura, à direita). Deve-se ressaltar que as temperaturas diminuíram comparativamente aos valores obtidos às $15 \mathrm{~h}$, no entanto, o centro urbano continua com temperaturas mais elevadas que a área rural desse município. A temperatura predominante na área rural é de $33^{\circ} \mathrm{C}$, aproximadamente, enquanto na área urbana a temperatura é superior a $34^{\circ} \mathrm{C}$. 


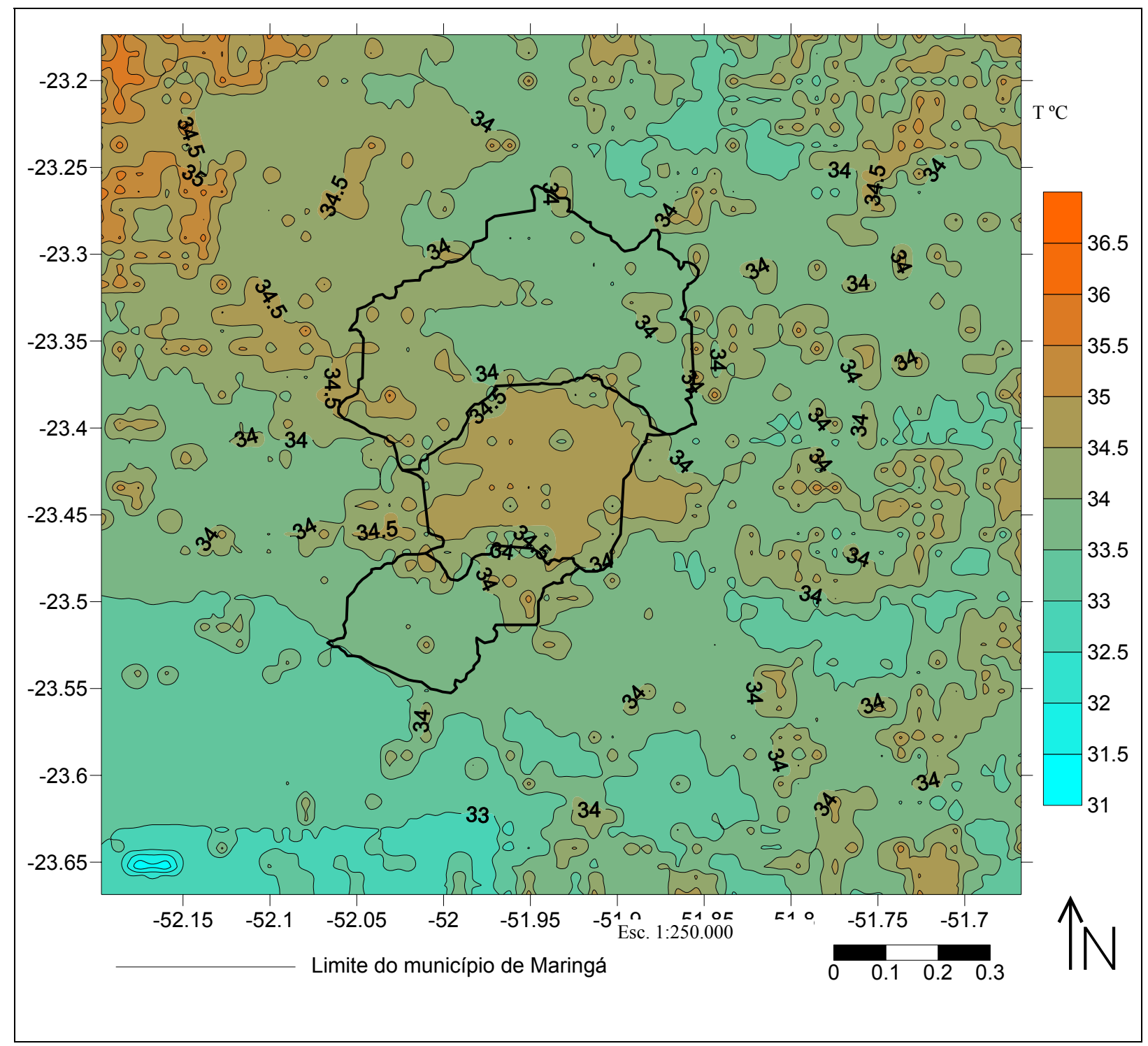

Na Figura 7B, pode-se observar a direção e intensidade do vento obtido pelo modelo. Os ventos das $18 \mathrm{~h}$ (verão), comparativamente aos ventos das $15 \mathrm{~h}$ estão significativamente atenuados, com direção predominante na área urbana (metade inferior do cone urbano), com ventos de sudeste e intensidade variando de $3 \mathrm{a} 4 \mathrm{~m} / \mathrm{s}$. Já a metade superior da área urbana apresentou direção leste, com intensidade de 2 a $3 \mathrm{~m} / \mathrm{s}$. Há variabilidade na direção dos ventos, nos solos expostos, mas com intensidade média de $3 \mathrm{~m} / \mathrm{s}$.

Deve-se ressaltar a importância da radiação incidente sobre a região, gerando intenso gradiente térmico entre os dois períodos analisados, provocando significativa variabilidade na intensidade e direção do vento. Por se tratar de uma área relativamente pequena, os efeitos térmicos são altamente significativos nessa primeira aproximação dada pelo modelo, utilizado nesse trabalho. 
Com o objetivo de analisar a dinâmica da circulação dos ventos na área de estudo, bem como as isotermas, utilizou-se o modelo TVM, para simular essa dinâmica, retirando a topografia. É de conhecimento científico que a rugosidade do solo, provoca turbulências na região analisada, modificando a direção e a intensidade do vento. Desta forma a proposta nessa etapa do trabalho, foi simular as condições dinâmicas da região para estudar a importância da topografia na orientação dos ventos, além da variabilidade da temperatura do solo.

FIGURA 7B - RESULTADO OBTIDO ATRAVÉS DO MODELO: ANÁLISE DAS ISOTERMAS, NA SUPERFÍCIE, E DIREÇÃO DO VENTO ÀS 18 HORAS

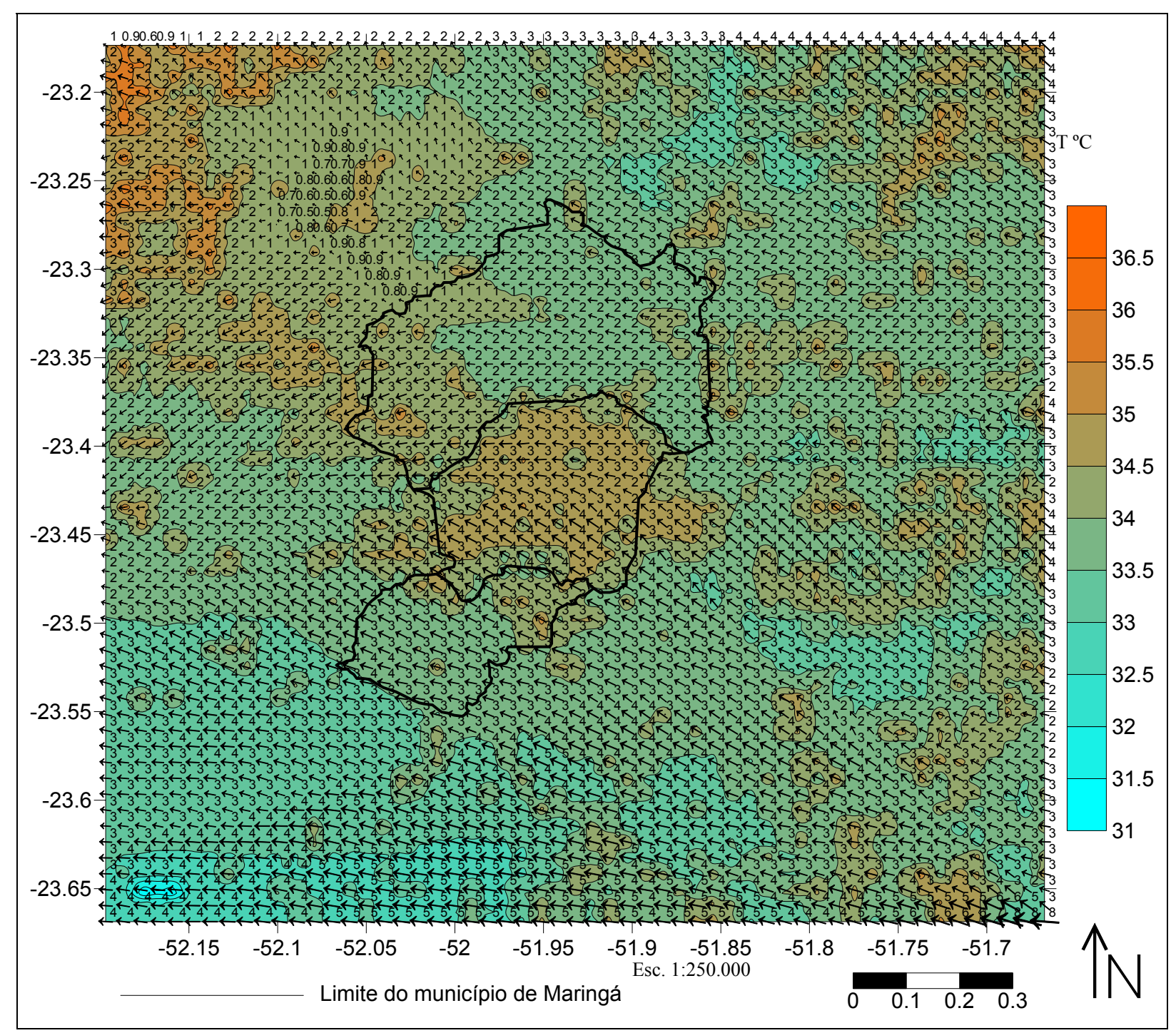

Na Figura 8A, são apresentadas as isotermas, espacialmente distribuídas para às $15 \mathrm{~h}$, geradas a partir do modelo, retirando a topografia. Pode-se observar significativo gradiente térmico de $10^{\circ} \mathrm{C}$, com maiores temperaturas na região de solos expostos (temperatura de, aproximadamente, $42^{\circ} \mathrm{C}$ ) e menores temperaturas, no rio Ivaí (aproximadamente $32^{\circ} \mathrm{C}$ ). Dentro do cone urbano o gradiente térmico foi de $1^{\circ} \mathrm{C}$, não havendo, portanto significativa variabilidade térmica nessa região. 
Observou-se na Figura 8A (sem considerar a topografia) uma temperatura menor, de 32 a $43^{\circ} \mathrm{C}$, em relação à Figura $6 \mathrm{~A}$ (considerando a topografia) que apresentou uma variação de 33 a $44.5^{\circ} \mathrm{C}$, onde se pode inferir que a topografia interfere na temperatura local, ainda que o gradiente térmico não seja acentuado.

FIGURA 8A - RESULTADO OBTIDO ATRAVÉS DO MODELO: ANÁLISE DAS ISOTERMAS, NA SUPERFÍCIE, ÀS 15 HORAS, SEM CONSIDERAR A TOPOGRAFIA DA REGIÃO.

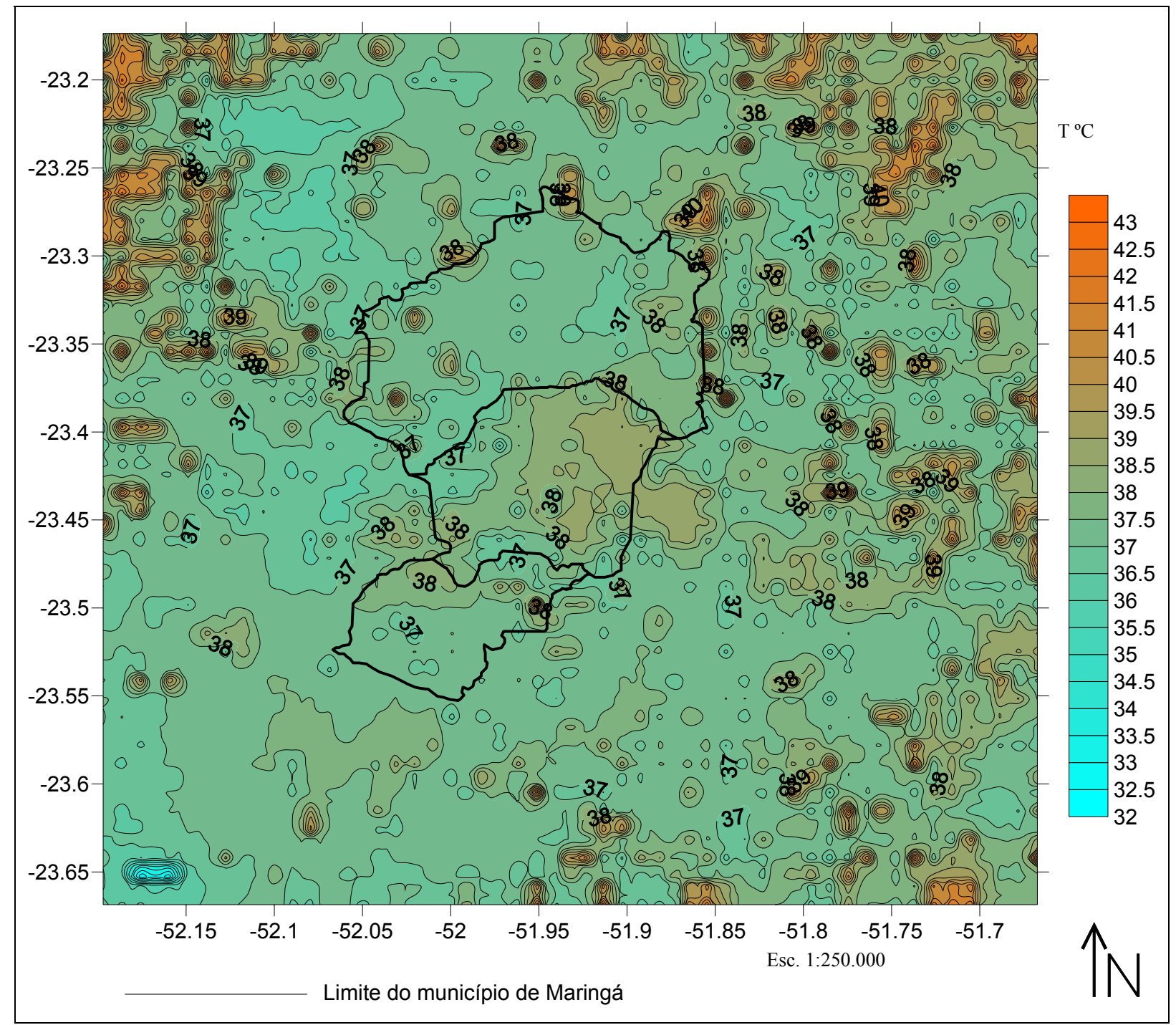

Na Figura 8B, pode-se observar os ventos mais intensos no centro urbano com intensidade variando de 2 a $5 \mathrm{~m} / \mathrm{s}$, predominantemente de norte. Já a metade superior da área urbana apresentou com intensidade abaixo de $1 \mathrm{~m} / \mathrm{s}$ a $3 \mathrm{~m} / \mathrm{s}$. Na metade inferior predominam ventos de menos de $1 \mathrm{~m} / \mathrm{s}$ com direção sul. Na Figura 6B (com topografia) observou-se ventos mais intensos na metade superior e inferior comparativamente com a Figura 8B, com diferenças de até $5 \mathrm{~m} / \mathrm{s}$. Assim pode-se inferir que a topografia também tem influência sofre a intensidade dos ventos, o que já era esperado. 
FIGURA 8B - RESULTADO OBTIDO ATRAVÉS DO MODELO: ANÁLISE DAS ISOTERMAS, NA SUPERFÍCIE, E DIREÇÃO DO VENTO ÀS 15 HORAS, SEM CONSIDERAR A TOPOGRAFIA DA REGIÃO

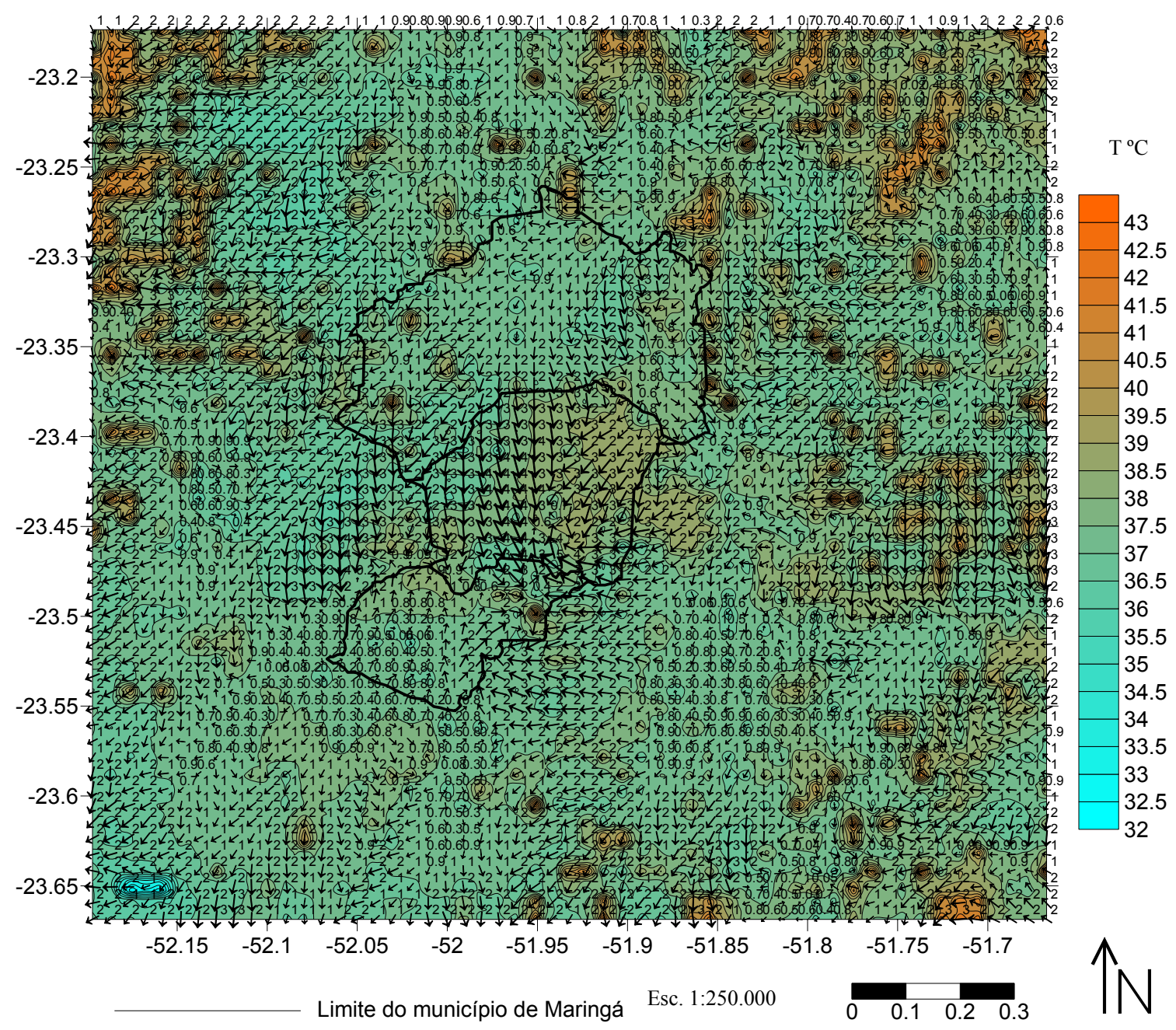

$\mathrm{Na}$ Figura 9A, são apresentadas as isotermas geradas pelo modelo, para as $18 \mathrm{~h}$, sem topografia. Pode-se observar em toda a área de estudo um gradiente térmico de $3.5^{\circ} \mathrm{C}$, com temperatura de $31^{\circ} \mathrm{C}$ (na área rural) e de $34.5^{\circ} \mathrm{C}$ (na área urbana e solo exposto). A temperatura no rio Ivaí (extremo inferior esquerdo da figura) a temperatura é de $31^{\circ} \mathrm{C}$. 
FIGURA 9A - RESULTADO OBTIDO ATRAVÉS DO MODELO: ANÁLISE DAS ISOTERMAS, NA SUPERFÍCIE, ÀS 18 HORAS, SEM CONSIDERAR A TOPOGRAFIA DA REGIÃO.

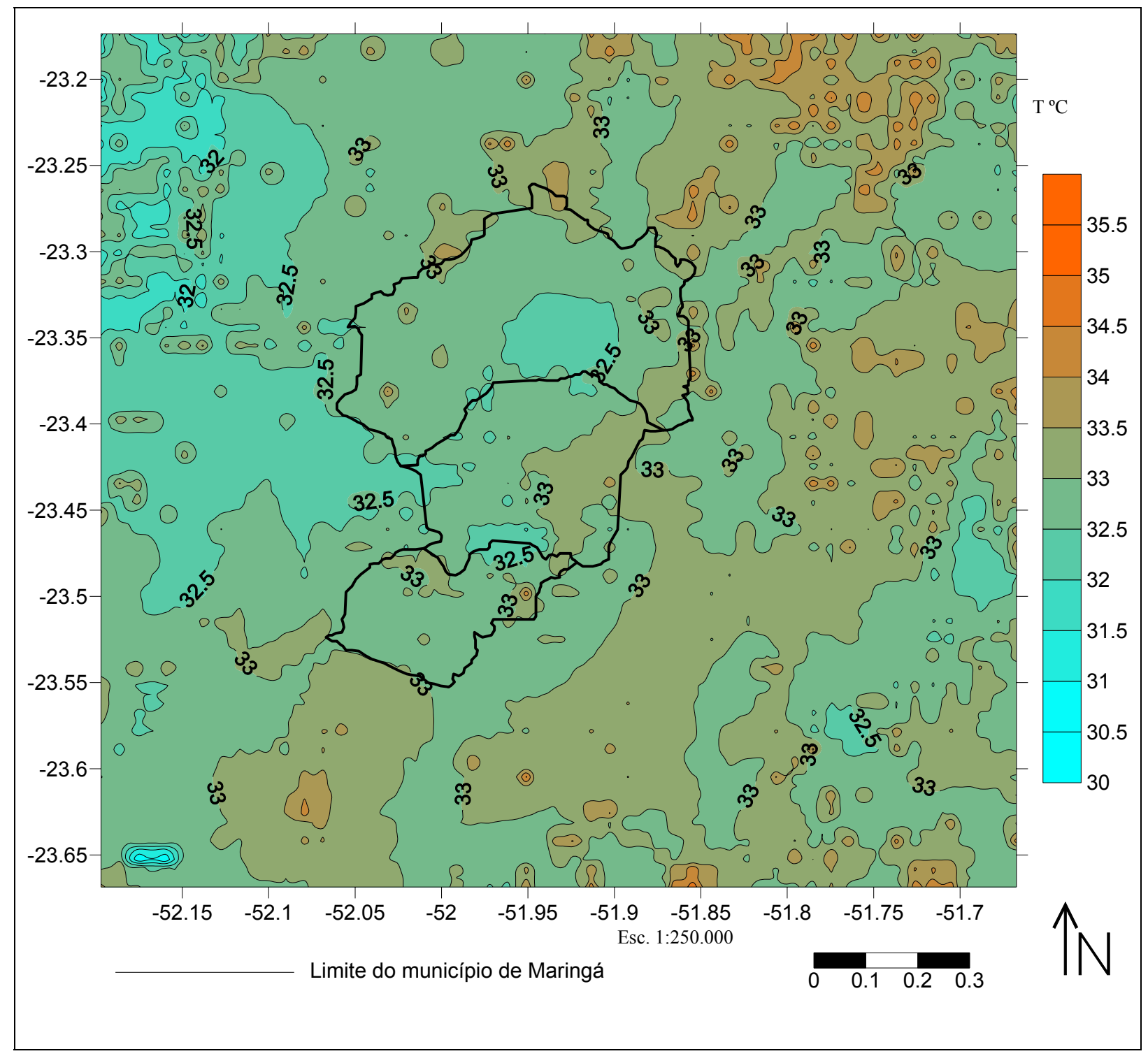

Em relação à intensidade e direção do vento, analisadas através do modelo, para as $18 \mathrm{~h}$, sem topografia (Figura 9B): observou-se, na área urbana, significativa variabilidade na direção desse parâmetro meteorológico, com ventos na direção leste, ao norte da área urbana, ventos na direção noroeste, a leste, ventos na direção norte, na parte centro - sul dessa área, mas todos com baixa intensidade (aproximadamente $1 \mathrm{~m} / \mathrm{s}$ ). Já a nordeste da área total estudada, os ventos têm intensidade de $2 \mathrm{~m} / \mathrm{s}$, aproximadamente, com direção sudoeste. De maneira geral, os ventos têm significativa variabilidade na direção, mas baixa intensidade, com valores máximos de $2 \mathrm{~m} / \mathrm{s}$, na área de estudo. 
FIGURA 9B - RESULTADO OBTIDO ATRAVÉS DO MODELO: ANÁLISE DAS ISOTERMAS, NA SUPERFÍCIE, E DIREÇÃO DO VENTO ÀS 18 HORAS, SEM CONSIDERAR A TOPOGRAFIA LOCAL

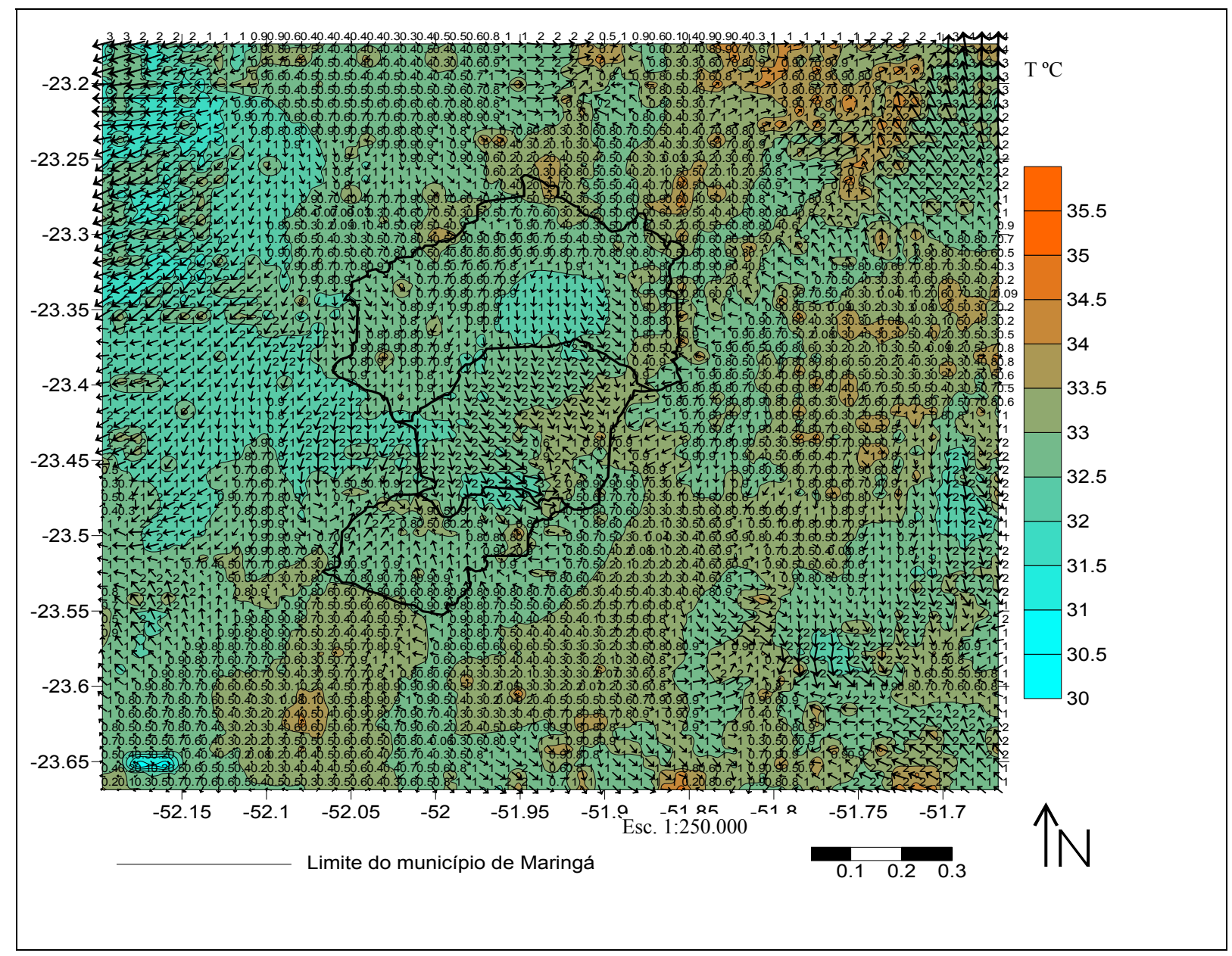

\section{Evolução Temporal da Temperatura}

Foram escolhidos pontos dentro da grade de uso de solo, obtida do Spring, que representam um tipo de uso de solo classificado (Figura 3) e feito um estudo da evolução temporal da temperatura.

As Figuras 10 a 13 referem-se a simulação do modelo TVM, onde foram analisadas a evolução das temperaturas do solo e a $15 \mathrm{~m}$ de altura.

A Figura 10 apresenta a evolução temporal da temperatura na superfície do solo e em $15 \mathrm{~m}$ para a superfície urbana. Pode-se observar que a temperatura no nível do solo teve uma maior variabilidade comparativamente a temperatura em $15 \mathrm{~m}$, apresentando uma temperatura máxima de aproximadamente $37.5^{\circ} \mathrm{C}$, às $13 \mathrm{~h}$, com uma variabilidade de $14^{\circ} \mathrm{C}$. A temperatura em $15 \mathrm{~m}$ apresentou um máximo de aproximadamente $31^{\circ} \mathrm{C}$ às $16 \mathrm{~h}$, com uma variabilidade de aproximadamente $6^{\circ} \mathrm{C}$. 
FIGURA 10 - EVOLUÇÃO TEMPORAL DA TEMPERATURA PARA UM SOLO URBANO PARA 10/01/05

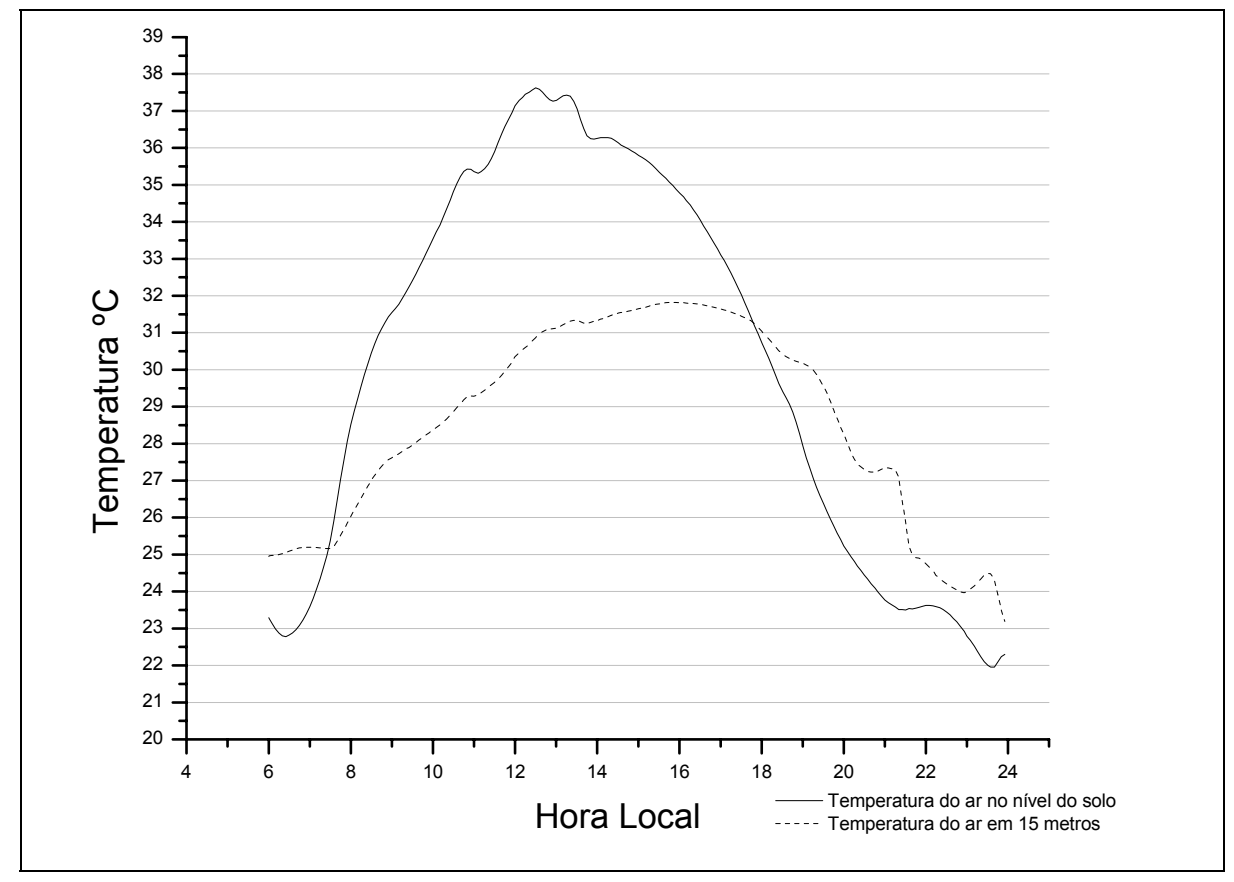

Na Figura 11 observou-se também uma maior variabilidade da temperatura no nível do solo comparativamente a temperatura em $15 \mathrm{~m}$, atingindo seu máximo com aproximadamente $36^{\circ} \mathrm{C}$ às $14 \mathrm{~h}$, apresentando, assim, uma variabilidade de $11^{\circ} \mathrm{C}$. A temperatura do ar em $15 \mathrm{~m}$ atingiu seu máximo às $16 \mathrm{~h}$ com uma temperatura de aproximadamente $33.3^{\circ} \mathrm{C}$ e uma variabilidade em torno de $8^{\circ} \mathrm{C}$.

FIGURA 11- EVOLUÇÃO TEMPORAL DA TEMPERATURA PARA UM SOLO COM VEGETAÇÃO ALTA PARA 10/01/05

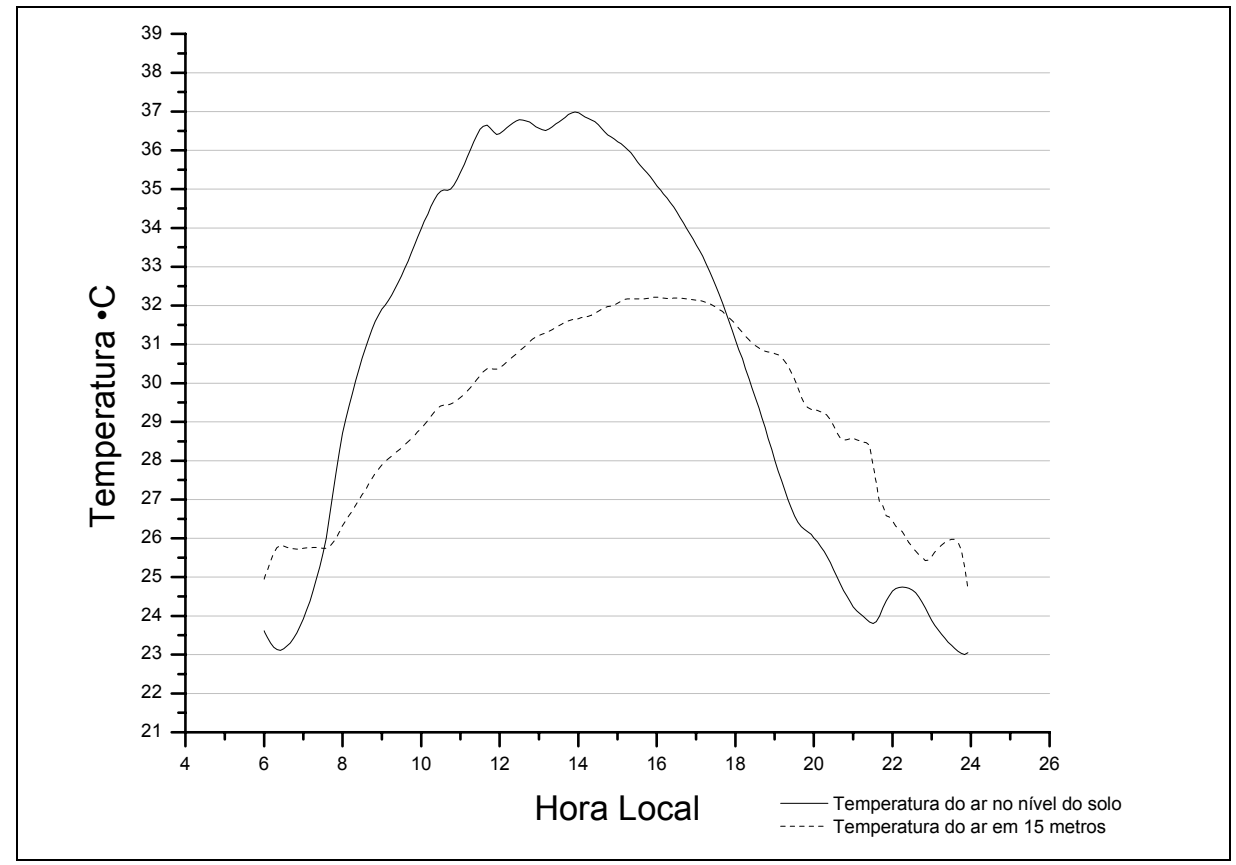


Para um solo com vegetação baixa, a Figura 12 mostra uma temperatura máxima de aproximadamente $35.5^{\circ} \mathrm{C}$ no nível do solo às $13 \mathrm{~h}$ e uma variabilidade de $13.5^{\circ} \mathrm{C}$ aproximadamente, já a temperatura do ar em $15 \mathrm{~m}$ apresentou mais uma vez uma temperatura máxima às $16 \mathrm{~h}$ em torno de $32^{\circ} \mathrm{C}$.

FIGURA 12 - EVOLUÇÃO TEMPORAL DA TEMPERATURA PARA UM SOLO COM VEGETAÇÃO BAIXA PARA 10/01/05

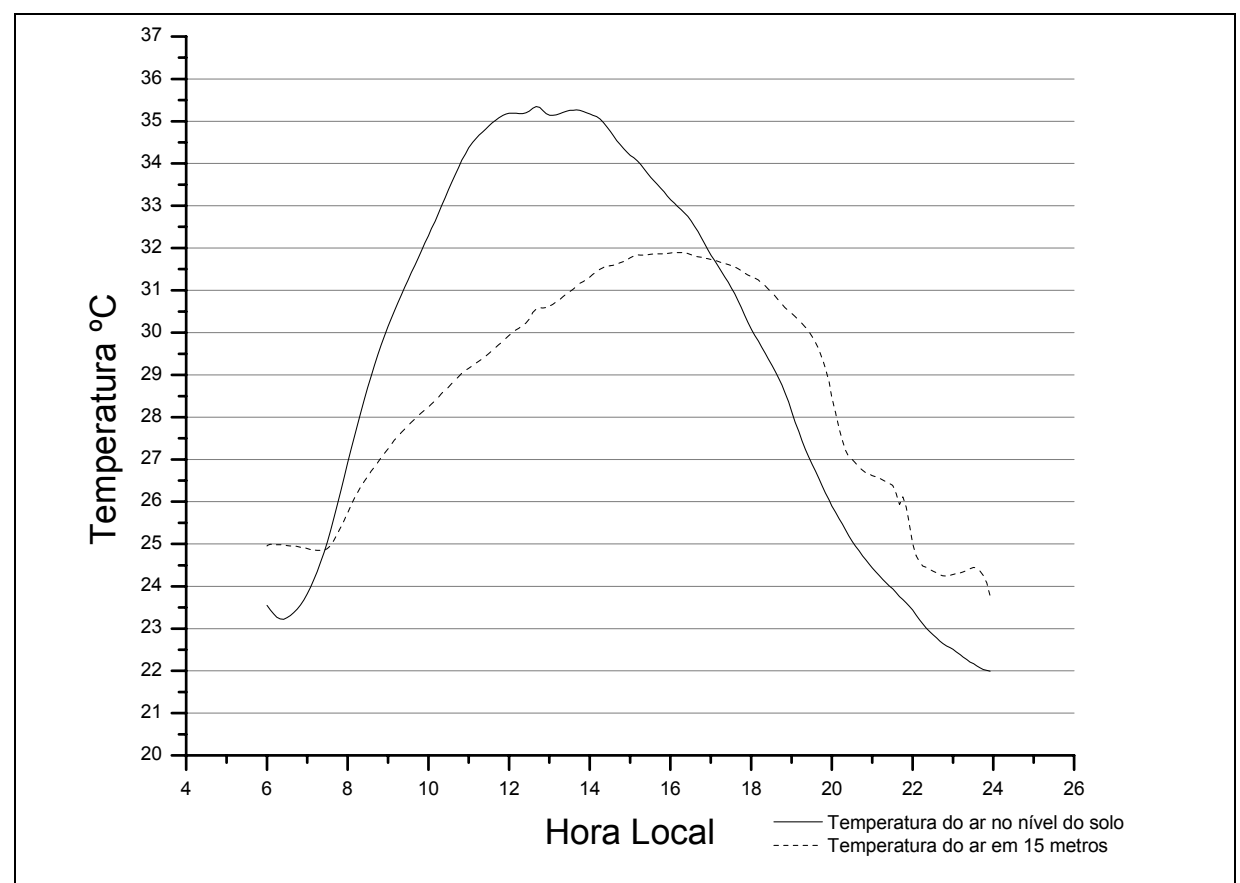

Para um solo exposto, a Figura 13 mostra uma temperatura máxima de mais de $36^{\circ} \mathrm{C}$ no nível do solo, mas agora às $12 \mathrm{~h}$ e uma variabilidade de $34.5^{\circ} \mathrm{C}$ aproximadamente, já a temperatura do ar em $15 \mathrm{~m}$ apresentou mais uma vez uma temperatura máxima às $16 \mathrm{~h}$ em torno de $32.5^{\circ} \mathrm{C}$.

FIGURA 13 - EVOLUÇÃO TEMPORAL DA TEMPERATURA PARA UM SOLO EXPOSTO PARA $10 / 01 / 05$

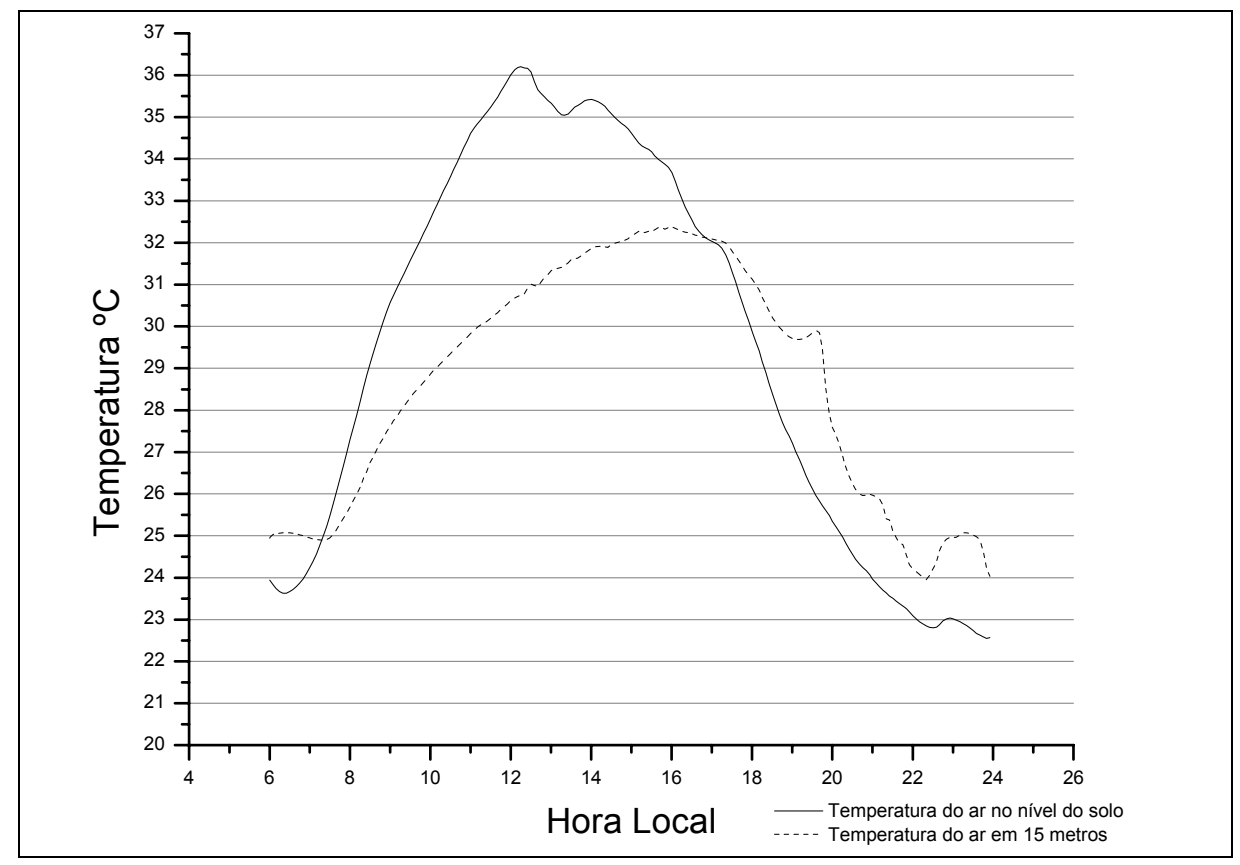




\section{Simulação do Balanço de Energia}

As Figuras 14 a 16 referem-se à simulação do balanço de energia pelo modelo TVM das 6 às 24h. Observou-se na Figura 14, que, após o nascer do sol (às 6h), houve um rápido aumento de calor latente, mais acentuado entre as 12 e $15 \mathrm{~h}$ com máximo às $14 \mathrm{~h}$. O calor sensível apresentou menor variação com seu máximo às $13 \mathrm{~h}$. Às $18 \mathrm{~h}$, horário considerado de pôr de Sol, as forças termais deixam de atuar, estabilizando-se as variáveis analisadas. Desta forma pode-se inferir que significativa percentagem de energia solar incidente sobre essa região foi utilizada para aquecimento da cidade (observar fluxo de calor sensível, H) e para a evaporação dos materiais constituintes dessa área urbana. Pouca energia foi transmitida para o solo (G).

FIGURA 14 - EVOLUÇÃO DO BALANÇO DE ENERGIA PARA UM SOLO URBANO PARA 10/01/05.

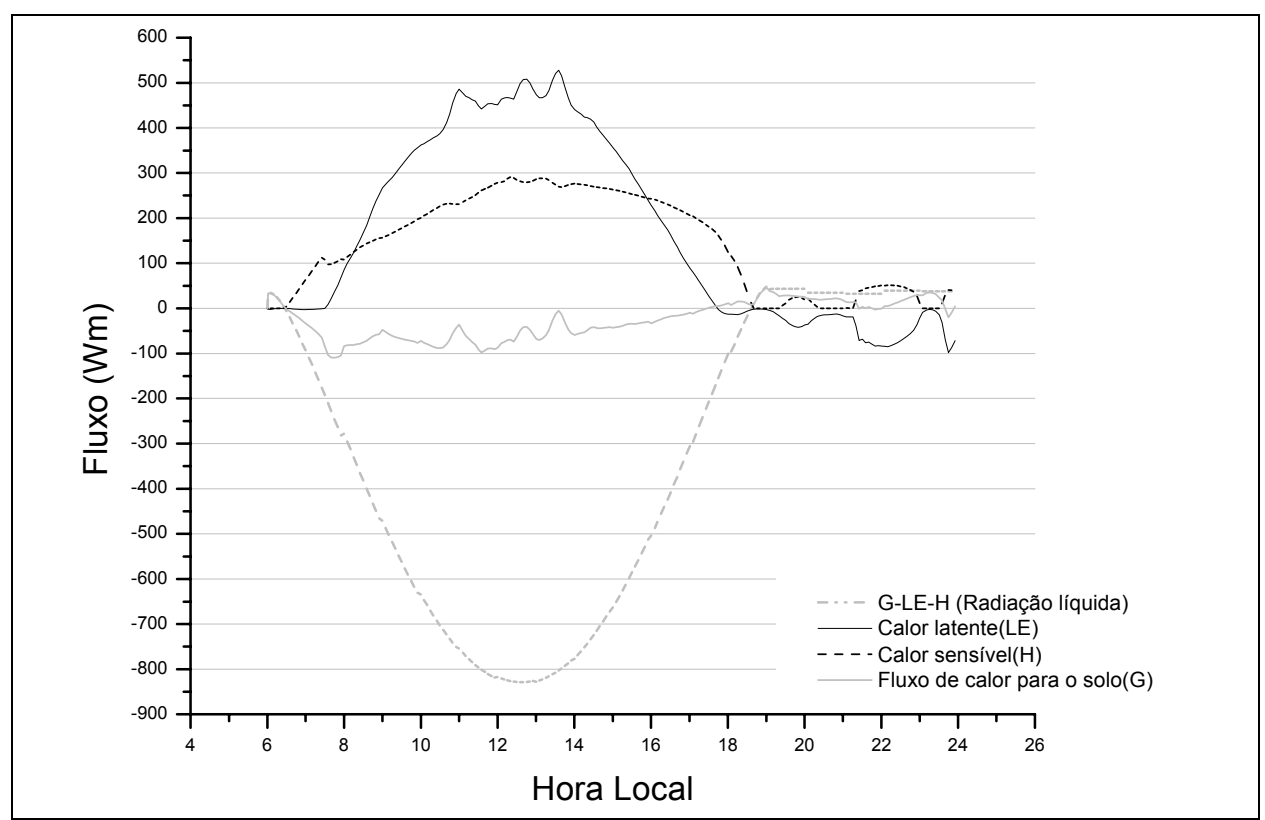

Na Figura 15 observou-se uma grande semelhança com o balanço de energia apresentado na Figura 14 (urbano). Após o nascer do Sol (às 6h), houve um rápido aumento de calor latente, mais acentuado entre as 12 e $15 \mathrm{~h}$. O calor sensível apresentou menor variação com seu máximo às $13 \mathrm{~h}$. Desta forma pode-se inferir que significativa percentagem de energia solar incidente sobre essa região foi utilizada para aquecimento (observar fluxo de calor sensível, H) e para a transpiração das árvores. Desta forma tem-se que essas áreas apresentam-se consideravelmente frescas, pois além da energia utilizada para a sua fotossíntese, grande parte da mesma não consegue atingir as áreas inferiores ao dossel dessa vegetação. 
FIGURA 15 - EVOLUÇÃO DO BALANÇO DE ENERGIA PARA UM SOLO COM VEGETAÇÃO ALTA PARA $10 / 01 / 05$.

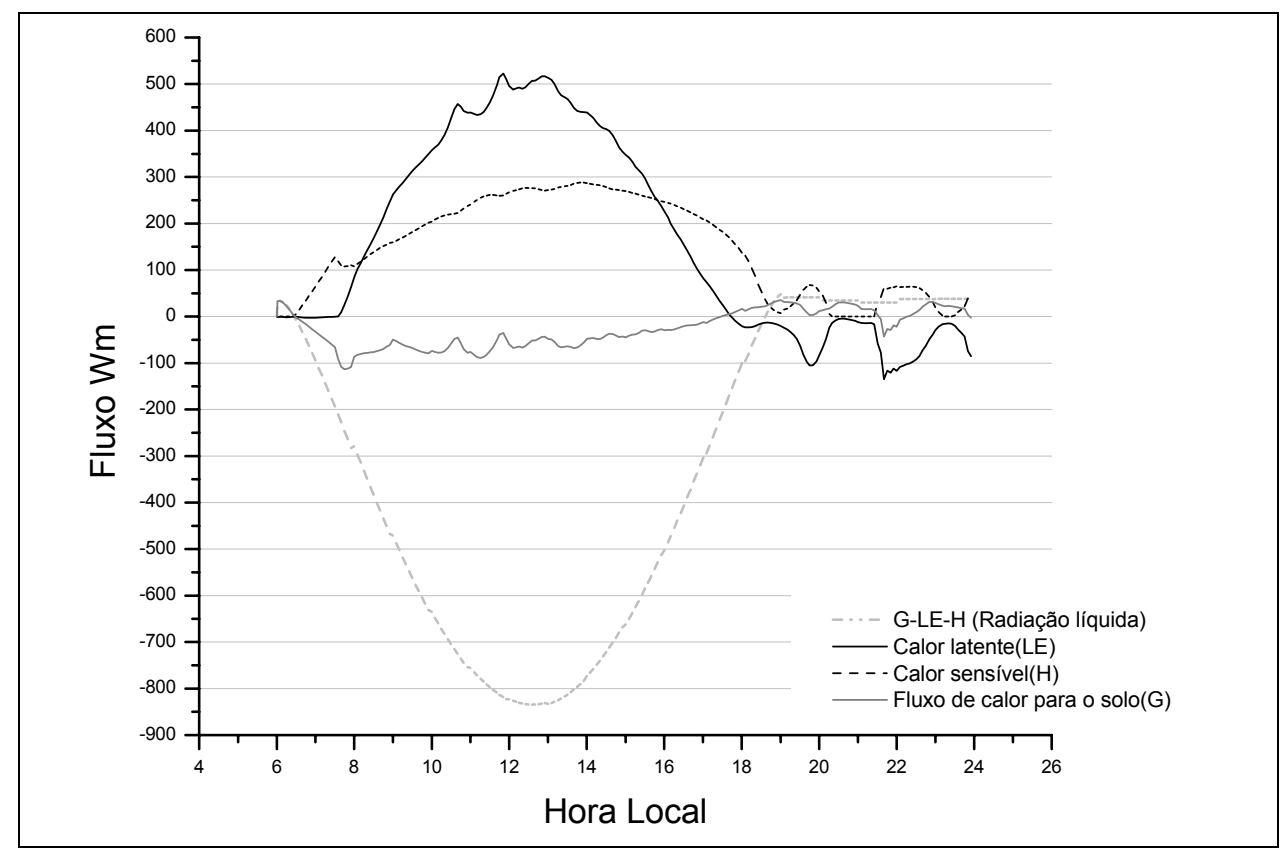

Na Figura 16 observou-se uma maior variação do calor sensível comparativamente ao calor latente, mostrando uma situação inversa do ocorrido para um solo urbano e com vegetação alta. O calor sensível apresentou seu ponto máximo em torno de $13 \mathrm{~h}$, o mesmo acontecendo com o calor latente. Para essa situação pode-se inferir que, no caso das vegetações baixas, a energia solar incidente, direta e/ou difusa, são utilizadas muito mais para o aquecimento do meio que para transformação da água do meio em vapor de água.

FIGURA 16 - EVOLUÇÃO DO BALANÇO DE ENERGIA PARA UM SOLO COM VEGETAÇÃO BAIXA PARA 10/01/05.

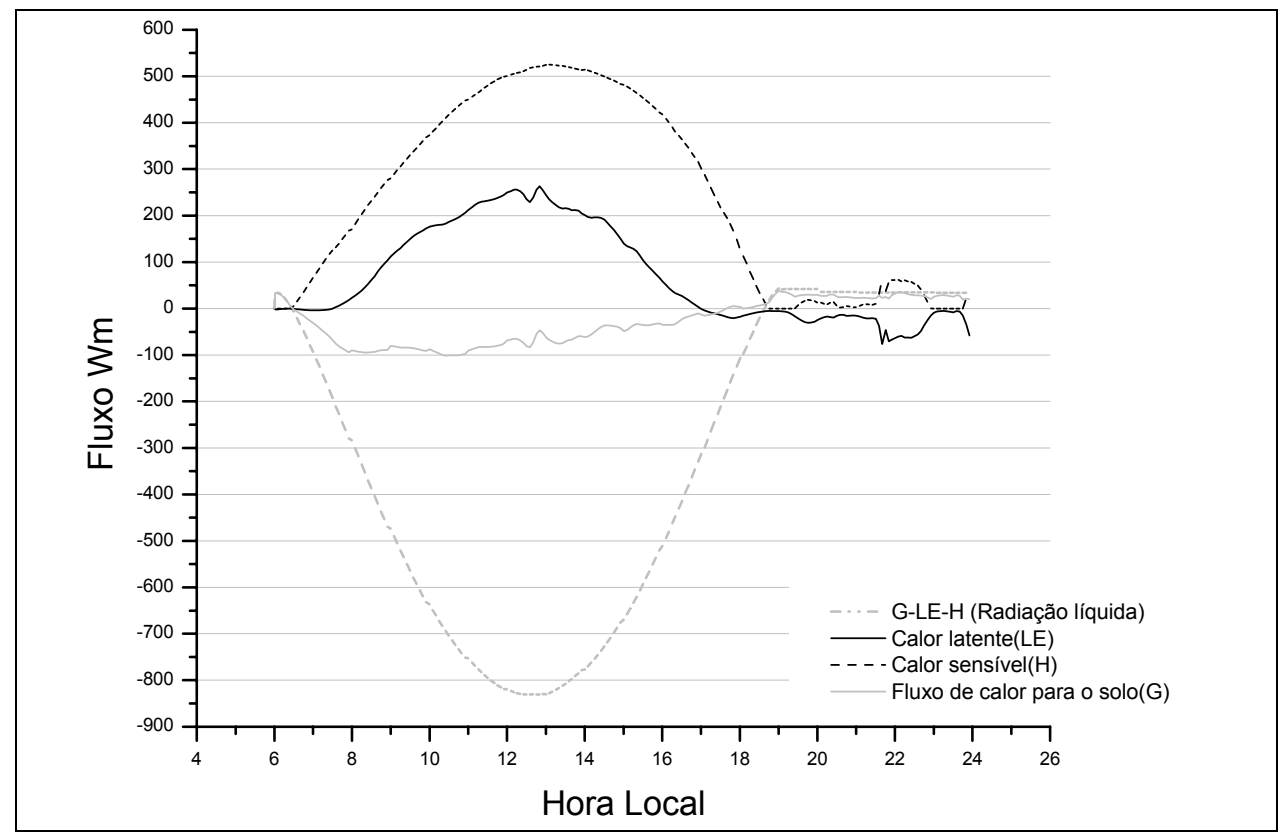




\section{CONCLUSÃO}

O modelo TVM apresentou grande similaridade com a realidade, mostrando as diferenças de temperaturas entre as áreas urbanas e rurais, o que se deve às propriedades térmicas dos materiais de construção.

O modelo simulou razoavelmente bem a direção e intensidade do vento, demonstrando que a topografia local é mais significativo que o campo térmico gerado pela cidade na determinação dos mesmos.

Neste estudo, onde se trabalhou com uma resolução de $1000 \mathrm{~m}$, não se pode observar a influência do asfalto e da arborização das ruas, mas se verificara a influência do parque do Ingá e Bosque 2, áreas marcadamente mais frescas, com temperaturas em torno de $1.5^{\circ} \mathrm{C}$ mais baixas.

Verificou-se ainda a importância da vegetação no declínio da temperatura quando a superfície (solo exposto) apresentou as primeiras temperaturas mais elevadas da área de estudo.

Sugere-se, em futuros trabalhos, utilizando o modelo TVM, que a escala seja alterado para valores menores que $500 \mathrm{~m}$, para possibilitar o estudo de ilhas de calor ou frescor, tornandose, portanto um estudo de Clima Urbano. Isso permitiria uma análise da influência no campo térmico da vegetação das ruas de Maringá.

\section{REFERÊNCIAS BIBLIOGRÁFICAS ${ }^{4}$}

BORNESTEIN, R. D. The two-dimensional URBIMET urban boundary layer. Journal Applied Meteorology n⿳114, 1459-1477, 1975.

BORNESTEIN, R.D. et al, Modeling the Polluted Coastal Urban Environmente: the PBL model. Eletric Power research Institute EPRI, Report EA-5091, vol.1, Research Project 1630$13,1986$.

Instituto Brasileiro de Geografia e Estatística - IBGE, Geografia do Brasil: Região Sul. V.5, Rio de Janeiro, 1977.

Instituto Brasileiro de Geografia e Estatística - www.ibge.gov.br - 03/12/2005

KARAN, H. A. Simulação numérica tridimensional da Camada Limite Planetária em Iperó, São Paulo, São Paulo: Departamento de Ciências Atmosférica; Universidade de São Paulo, 1995, 112p. Dissertação de Mestrado.

KARAN, H. A. Simulação numérica da dispersão de $\mathrm{SO}_{2}$ na região de Candiota com um modelo Langrangeano. Bauru: Workshop on Air Pollution and Acid Rain, The Candiota Program, 1996.

LOMBARDO, M. A. Ilha de Calor nas Metrópoles: o exemplo de São Paulo. São Paulo: Editora Hucitec Ltda, 1985, 244 p.

MAACK, R. Geografia física do Estado do Paraná. $3^{\text {a }}$ edição, Curitiba: Imprensa Oficial do Paraná, 2002, 440p. 
NERY, J. T. Variabilidade da precipitação no Brasil Meridional. Maringá: Acta Scientiarum, v 24, n.6, p 1687 - 1695, 2002.

OKE, T. R. City size and the urban heat island. Atmospheric Environment. Vol. 7, 769779, 1973.

SCHAYES, G. THUNIS, P. The three-dimensional mesoscale model in vorticity mode (TVM). Contribution 60, Institut d'Astronomie et de Geophysique Georges Lemaitre, Université Catholique de Louvain, Louvain-la-Nueuve, Belgium, 1990, 42p.

SPIRN, A. W. O Jardim de Granito: a natureza no desenho da cidade. São Paulo: Editora da Universidade de São Paulo, 1995, 345 p.

STIVARI, S. M. Um estudo da brisa lacustre do lago de Itaipu. São Paulo: Departamento de Ciências Atmosféricas; Universidade de São Paulo, 1999, 126p. Tese de Doutorado em Ciências Atmosféricas.

THUNIS, P.; CLAPPIER, A. Formulation and evaluation of a nonhydrostatic mesoscale vorticity model. Monthly Weather: Review $128 n^{\circ}$ 9, 3236-51 S, 2000, 23p. 